University of Nebraska - Lincoln

DigitalCommons@University of Nebraska - Lincoln

10-19-1964

\title{
Observation of Autoionization Levels in He by Positive Ion Bombardment
}

M. Eugene Rudd

University of Nebraska - Lincoln, erudd@unl.edu

Follow this and additional works at: https://digitalcommons.unl.edu/physicsrudd

Part of the Physics Commons

Rudd, M. Eugene, "Observation of Autoionization Levels in He by Positive Ion Bombardment" (1964). M. Eugene Rudd Publications. 38.

https://digitalcommons.unl.edu/physicsrudd/38

This Article is brought to you for free and open access by the Research Papers in Physics and Astronomy at DigitalCommons@University of Nebraska - Lincoln. It has been accepted for inclusion in M. Eugene Rudd Publications by an authorized administrator of DigitalCommons@University of Nebraska - Lincoln. 


\title{
PHYSICAL REVIEW LETTERS
}

\begin{tabular}{lccc}
\hline Volume 13 & 19 OCTOBER 1964 & Number 16 \\
\hline
\end{tabular}

\section{OBSERVATION OF AUTOIONIZATION LEVELS IN He BY POSITIVE ION BOMBARDMENT*}

\author{
M. Eugene Rudd \\ Concordia College, Moorhead, Minnesota \\ (Received 21 September 1964)
}

Certain highly excited energy levels in helium have been observed optically ${ }^{1}$ and by inelastic electron scattering, ${ }^{2}$ and have been calculated theoretically. ${ }^{3}$ Reported here is the observation of these levels by the measurement of the energy spectrum of electrons emitted after bombardment with protons and hydrogen molecular ions. Some of the states show up clearly by this method which are weak or absent in the other techniques. Berry ${ }^{4}$ has previously observed autoionization of helium by this method, but his measurements lacked the resolution necessary to identify the states.

The apparatus consisted of a collision chamber with a parallel-plate electrostatic analyzer and an electron multiplier detector. Individual electrons were counted. The equipment was designed to make measurements of the angular and ener gy dependence of the cross sections for ejection of electrons from gases by positive ions and is similar to one described previously. ${ }^{5}$ Magnetically selected protons or molecular ions from the Concordia Cockroft-Walton accelerator were the bombarding particles. The analyzer was calibrated by making careful measurements with an electron gun source and from the same data the resolution of the analyzer was also determined. The shape of the resolution curve was nearly triangular with a full width at half maximum of about $3 \%$. The electrons were decelerated by 20 volts before entering the analyzer during the measurements with the ion beam, resulting in a resolution which varied from $0.36 \mathrm{eV}$ at $32 \mathrm{eV}$ to $0.66 \mathrm{eV}$ at $42 \mathrm{eV}$.

The observed energy spectrum consists of a continuous background due to "ordinary" collisional excitation, with a superimposed "line" spectrum due to the autoionizing states. Electrons ejected in a direction nearly opposite that of the ion beam $\left(160^{\circ}\right)$ were used in these measurements since the ordinary cross section is smallest there and the lines stand out most prominently. The lines were still visible, however, at other angles. The helium pressure in the collision chamber was about 1.6 microns for the molecular ion data and about 2.8 microns for the proton data. The bombarding energy in both cases was $75 \mathrm{keV}$ although the states have been observed at ion energies from $25 \mathrm{keV}$ to $250 \mathrm{keV}$. While no systematic determination of the dependence of the line intensities on ion energy has been made, it appears that the lines become less prominent as the energy is increased above 75 keV.

The energy spectra are shown in Figs. 1 and 2. The energy of the ejected electrons differs from the excitation energy by the ionization potential of the gas, in this case $24.6 \mathrm{eV}$. The values of the energy levels and their designations as calculated by Burke, McVicar, and $\mathrm{Smith}^{3}$ are marked in Fig. 1. The levels at 57.8, 58.3, 60.1, and $62.9 \mathrm{eV}$ are in good agreement with the theoretical values. At higher energies the peaks are not as clearly defined and, because the uncertainty due to statistical fluctuations is about as great as some of the peaks, the lines were not 


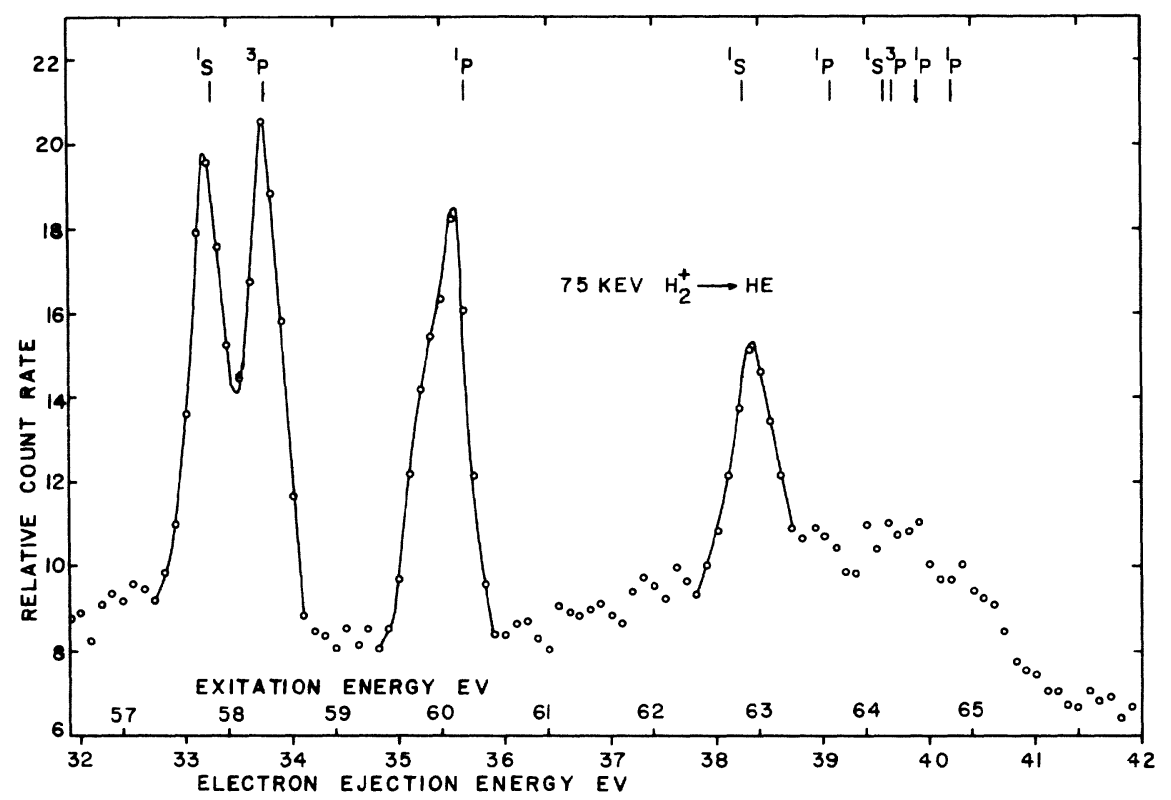

FIG. 1. Counting rate in arbitrary units vs ejected electron energy for $75-k e V$ hydrogen molecular ions incident on helium gas.

drawn in. However, there appear to be small peaks associated with most of the higher energy theoretical values also. Additional small peaks at 61.9 and $62.2 \mathrm{eV}$ were fairly reproducible.

As seen in Fig. 2 the $58.3-\mathrm{eV}$ level is not excited by proton bombardment although it is strongly excited by hydrogen molecular ions. This level is only very weakly excited in the elec- tron scattering work. ${ }^{2}$ Likewise, the $62.9-\mathrm{eV}$ level is much more prominent with the molecular beam than with either protons or electrons. In Fig. 1 the widening of the $60.1-\mathrm{eV}$ peak on the low energy side may be due to excitation of ${ }^{1} D$ level at $60.0 \mathrm{eV}$ reported by Simpson, Mielczarek, and Cooper. ${ }^{2}$

Using the molecular beam, the 18 - to $20-\mathrm{eV}$

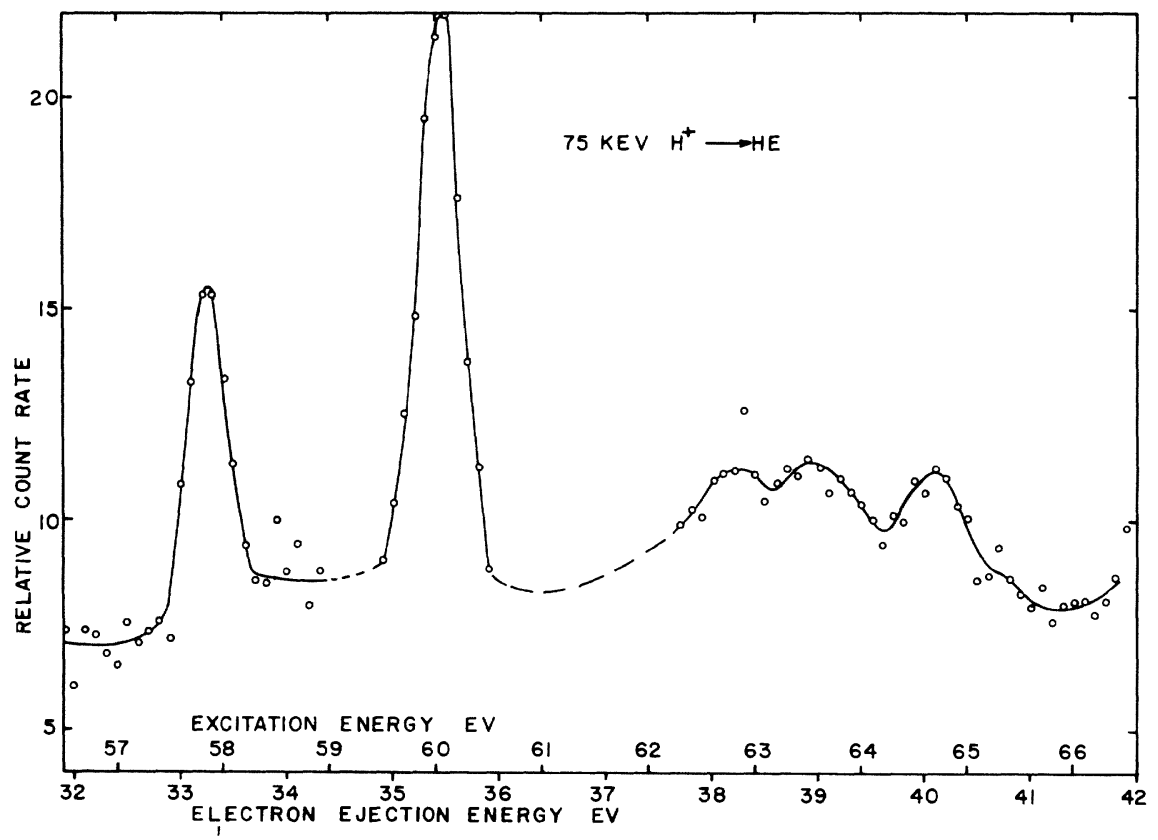

FIG. 2. Counting rate in arbitrary units vs ejected electron energy for $75-\mathrm{keV}$ protons incident on helium gas. 
region has also been searched for possible evidence of the resonance observed by Schulz ${ }^{6}$ using electron scattering. At best only a very small peak was observed, hardly distinguishable above the statistical variations in the counting rate. Additional work is planned using other gases.

The author wishes to thank Dr. Carl Bailey and Dr. Chris Kuyatt for stimulating discussions, and David Lang and Dwain Gregoire for their valuable assistance in taking the data.
*Work supported in part by the U. S. Atomic Energy Commission.

${ }^{1}$ R. P. Madden and K. Codling, Phys. Rev. Letters $\underline{10}, 516$ (1963).

${ }^{2} \mathrm{~J}$. Arol Simpson, S. R. Mielczarek, and J. Cooper, J. Opt. Soc. Am. 54, 269 (1964).

${ }^{3}$ P. G. Burke, D。D. McVicar, and K. Smith, Phys. Rev. Letters 11, 559 (1963).

${ }^{4}$ H. W. Berry, Phys. Rev. 127, 1634 (1962).

${ }^{5}$ M. E. Rudd and T. Jorgensen, Jr。, Phys. Rev. 131, 666 (1963)

${ }^{6}$ G. J. Schulz, Phys. Rev. Letters 10, 104 (1963). 